\title{
THE MARKET ENVIRONMENT - INVESTMENT CONSTRAINTS
}

\author{
ProfessorPhD Ioan E. Nistor, inistor@econ.ubbcluj.ro \\ PhD student Viorela-Ligia Văidean, vvaidean@econ.ubbcluj.ro \\ "Babeş-Bolyai" University Cluj-Napoca \\ Faculty of Economics and Business Administration, Finance Department
}

\begin{abstract}
A wide variety of investment choices are analyzed by investors on turn, in the broad context of legal, regulatory and tax environments. According to their preferences, investors make strategic choices, foreseeing to each category of potential risk and reward. Worldwide tax policies may either promote or deter certain market behaviors, influencing both the investors' and the issuers' decisions. The judicial infrastructure of a given market is most likely something to be taken for granted. Furthermore, self-imposed constraints and formal restrictions have a great impact upon investors acting on the market, so different national regulations are analyzed on turn.
\end{abstract}

When it comes to financial engineering principles, a great stress must be laid upon the market environment. This macro orientation is focused on taxes, legal issues and investor-related issues.

\section{TAX}

A non-homogenous application of taxes actually gives rise to market opportunities as tax policy may either promote or deter certain market behaviors, influencing both the investors' and the issuers' decisions. Unless one is investing in a non-profit entity, paying taxes has a very large impact upon an investor's decision making policies and upon his realized total returns.

The capital gains tax (CGT) is the tax charged on capital gains, i.e. the profit realized on the sale of an asset that was initially purchased at a lower price. It is not implemented in all countries and those who implement it have different rates of imposing it to individuals or to corporations. Most commonly, capital gains are realized from the sale of stocks, bonds and property.

Considering the example of the United States of America, as a well developed financial market, different tax structures apply. American individuals and corporations pay income tax on the net total of all their capital gains just as they do on other sorts of income. For equities and bonds, the capital gains ${ }^{1}$ tax is leveled into a short-term rate (the holding period is less than one year) and a long-term rate (the holding period is more than one year). As expected, the long-term capital gains tax rate is less than the short-term capital gains tax rate in order to motivate the investors to hold on to their investments and to discourage short-term profit-taking strategies. The tax rate on long-term gains was reduced in 2003 to $15 \%$, and to $5 \%$ for individuals in the lowest two income tax brackets. It's estimated that in 2011 these reduced tax rates will "sunset," or revert to the rates in effect before 2003, which were generally $20 \%$. Short-term capital gains are taxed at a higher rate: the ordinary income tax rate. As of 2006, there are six "tax brackets" ranging from $10 \%$ to $35 \%$. Ordinary income is taxed within the particular tax bracket listed on the rate schedules or tax tables as a percentage for each dollar within that bracket.

\footnotetext{
${ }^{1}$ capital gain $=$ profit that results from the sale or exchange of a capital asset over its purchase price. If the price of the
} capital asset has declined instead of appreciated, we have a capital loss. 
In Eastern Europe, we may consider Hungary's example. Since September 2006, there has been only one flat tax rate on capital income, of $20 \%$. It is applied whenever selling stocks, bonds and shares of mutual funds.

Our Southern neighbor, Bulgaria, has no capital gains tax at all.

Coming back to the United States of America, other instruments, such as coupons, are subject to tax at a non-investment-related tax rate. The fixed income instruments are subject to local taxes, state taxes or federal taxes and even a combination of the above.

Another issue that needs to be considered would be the relative performance of a given security under the most likely assumption that its year-end price would differ from its initial acquisition price. Capital gain and loss hypothesis are analyzed on turn. And above all these, the tax policy applied to the price difference has a major impact over decision making.

Further considering the example of municipal bonds, they are typically offered with some kind of tax free-status attached to them, so that the state and its municipal entities would have granted access to lower-cost financing sources. They are more attractive than corporate securities thinking of the municipality's ability to generate tax revenues as opposed to profits in a more traditional business sense: the investor is assured of a certain gain, although their revenue might be smaller.

In Romania, the gain or the loss from transfering securities represents the positive or negative difference between their selling price and their acquisition price, diminished with the costs of the transaction.

The net annual gain is determined by substracting the gains and the losses from transferring securities from that year. The gain from trading securities is imposed with $1 \%$ if they were kept for a period longer than a year. For the transactions taking place in a period shorter than a year, the $16 \%$ rate is applied.

To draw a conclusion upon tax matters, they can be of a great importance when it comes to developing a certain strategy and calculating one's total returns in order to decide in between investment opportunities.

\section{LEGAL AND REGULATORY}

The judicial infrastructure of a given market is most likely something to be taken for granted. Currency ratings are usually based on the independence and effectiveness of the legal environment existing on that market.

In order for a company to have its shares listed on a stock exchange, specific registration requirements are imposed not only by the exchange itself, but by governmental agencies as well. Listing requirements established by stock exchanges are the standards imposed to control membership in the exchange. Companies wishing to issue their stock on a given exchange must meet its listing requirements and continue to do so for as long as they are on the exchange. There is a series of general principles on which the requirements are based. Firstly, all applicants should be of a certain minimum size, quality and have a record of operations of adequate duration. Secondly, all holders of securities should be treated equitably and the listed issuers would always keep them fully informed of all facts that might affect their interests. Nevertheless, the directors of listed issuers and their officers should maintain the highest standards of integrity, accountability and responsibility.

While the particular requirements vary from one stock exchange to the other, the two most important categories of requirements deal with the size of the company (as defined by market capitalization or annual income) and the liquidity of the shares (a certain number of shares must already have been issued). For example, one of the listing requirements of the New York Stock Exchange for public companies is that the company must have at least 1,1 million publicly-traded shares outstanding that are worth at least 100 million USD. 
Bucharest Stock Exchange imposes certain listing requirements, too. For admission to the first rank listing, companies must have an equivalent equity of 8 million euro. Furthermore, for admission to the second rank listing, companies must have a 2 million euro equivalent equity and for admission to the third rank listing, i.e. the "new market", companies must have 1 million euro equity. This "new market" was especially designed for small societies, acting in dynamic sectors of the economy and also having a lot of potential, although they haven't had a rich history of activity. Another requirement for the first and second ranks refers to the annual rate of stock transacting for a specific issuer: $80 \%$ for the first category and $40 \%$ for the second category. Moreover, the daily average transactions must be of at least five transactions and at least two transactions, respectively. The average daily transactions for a first rank issuer must be of 25.000 lei and for a second rank issuer 2.000 lei respectively.

A fact that is valid most likely all over the world is that certain restrictions may be placed on how and when the equity is retained or sold by company insiders and the company's board of directors may be demanded to present their history of past dealings. It is a potential investor's clear advantage to know what the protection policy is and when the investment would involve an initial public offering.

Regarding currencies, transactions occur in an over the counter market as restrictions mostly apply to the amount and exchange rate ${ }^{2}$ of the cash transfer.

Bonds also are an over the counter market, yet national guidelines do exist in order to ensure the fairness of the buy-sell process.

And as the structure of financial instruments grows more complex, legal considerations may become more complex as well.

So far we have argued for the great impact of regulations on issuers.

\section{INVESTORS}

A wide variety of constraints, either self-imposed or imposed by others, affects investors acting on the market.

A good example of a self-imposed constraint may be the voluntary restriction set by fund managers when investing in certain types of derivatives or even a preset limit on how much they would leverage their portfolio.

Then, among American industry types that are subject to more formal restrictions on the way they can invest, banking and insurance are most certainly at the top of the list.

With banks, restrictions exist with investing in any type of equity product, as well as having to designate if the investments they have made are held for portfolio (a long-term investment) or available for sale (a short-term investment). Another restriction on bank investments relates to credit considerations. In particular, banks often are required by the government where they operate to follow strict formulas for how much capital must be set aside relative to the types of securities they have purchased. Many guidelines are taken directly from the Bank of International Settlements (BIS).

As stated, insurance companies are also subject to a variety of stringent rules of operation. Among the restrictions faced by insurance companies, there is an interdiction for investing in nondollar-denominated securities.

Regarding insurance regulations pertaining to American investment policy, this matter is generally handled on a state-by-state basis. To assist states with the drafting of appropriate law, the National Association of Insurance Commissioners (NAIC) has prepared so-called model laws. These proposals contain suggested limits or guidelines on various types of investments inclusive of

\footnotetext{
2 black market rate (for countries without freely floating market-determined exchange rate) or the officially set exchange rate
} 
mortgage products, securities denominated in currencies other than the dollar, securities lending, derivatives, and other matters.

To sum up, both voluntarily imposed or formally mandated investment rules will always be a key consideration for investors.

\section{CONCLUSION}

The very existence of various market rules and regulations (including taxes) may serve to create pockets of price dislocation in the marketplace. From a pure classical economic viewpoint, this is not very surprising. When economic agents act more in response to how someone else wants them to behave than to how they themselves might want to behave, distortions can well arise.

When such distortions are a necessary side-effect of commonly accepted principles of sound behavior (as with protecting the risks that banks or insurance companies might take to the detriment of consumers who rely on their sound business practices), such rules and regulations typically are embraced as necessary and reasonable. What particular rules, regulations, and tax policies

are helpful or not, and how best to create and enforce them, is a topic of considerable debate and review as long as there are markets.

SHAPE

Figure no. 1 Model of facto gcro market environment

Investors can view a variety BA Hestment chores in thEGAhtANBf legal, regulatory, and tax environments, and then make strategic choices accordingGU the fif Pfeferences and outlook regarding each category of potential risk and reward.

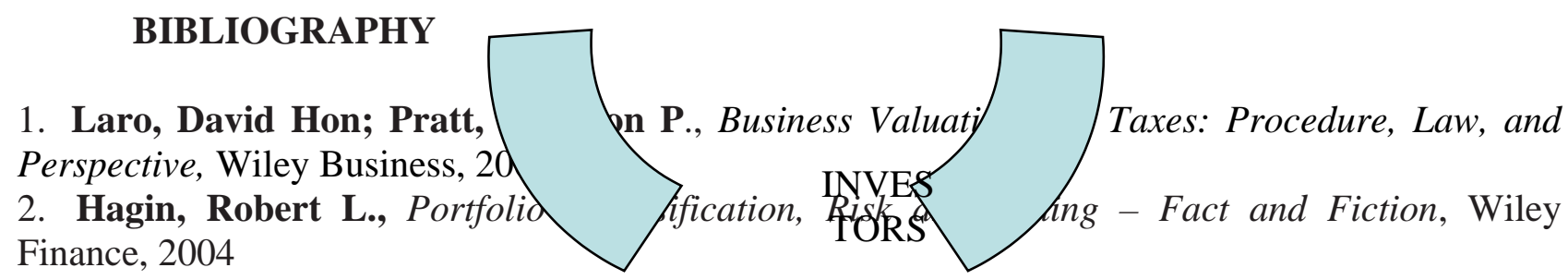

3. Beaumont, Perry H., Financial Engineering Principles: A Unified Theory for Financial

Product Analysis and Valuation, Wiley Finance, 2003

4. Bagley, Constance E., Dauchy Craig E., The Entrepreneur's Guide to Business Law, electronic edition, 2007

5. www.investopedia.com

6. www.smartfinancial.ro

7. www.smartmoney.com 